\title{
COST-EFFECTIVE DISTRIBUTED LEARNING WITH ELECTRONICS LABS
}

\author{
J. Olin Campbell, Ph.D. \\ Brigham Young University
}

John R. Bourne, Professor of Electrical and Computer Engineering, Franklin W. Olin College of Engineering, Professor of Technology Entrepreneurship, Babson College

Pieter J. Mosterman, The MathWorks, Inc.

Mahmood Nahvi, Electrical Engineering Department, Cal Poly State University

Rassa Rassai, Engineering/Electronics, Northern Virginia Community College

Arthur J. Brodersen, Electrical Engineering, Vanderbilt University

Martine Dawant, Director of Technical Operations, The Sloan Consortium

\begin{abstract}
Online learners can study at convenient times and collaborate with others online, but usually can not come to physical labs. We investigated the use of simulated electronics laboratories to increase access and decrease trips to a physical lab. Students were assigned to either physical labs or to a combination of simulated and physical labs. Students using combined virtual and physical labs performed as well as those using only physical labs on both written and physical lab tests. This evidence supports the use of virtual labs to replace some physical labs, including the use of virtual labs for online learners.
\end{abstract}

\section{KEYWORDS}

Online learning, computer-aided learning, cost effective laboratories, automated instructional design

\section{INTRODUCTION}

To what extent can we support online students whose learning requires lab work? With the increase in online distributed learning, we face an issue of access: the requirement for students to come to physical labs. Can we offer some virtual "hands-on" laboratory classes outside the physical laboratory setting so students do not need to make as many trips to physical labs? To answer this question, we investigated the use of simulations with embedded tutorials for beginning electronic circuits labs.

Several factors drive the effort to find alternatives for place-based labs. The first is access. In place-based education, labs can be costly, time-consuming, and difficult to schedule. Many students would prefer to work on labs late at night when faculty may have other commitments. 
A second factor is consistency. Implementation fidelity of learning programs in labs depends on TAs, who are often students themselves. The consistency of the learning experience may be low when the student works with different teaching assistants.

A third factor is the need to replace obsolete equipments with expensive new equipments. Low-cost simulations can replace some expensive physical equipment and decrease the amount and cost of equipment and increase access to up-to-date electronic laboratory experiences.

As use of simulations for circuit design becomes more common, use of simulations for learning circuit design makes sense. In many cases, as with aircrew training for emergency situations, simulations support a degree of engagement that would be enormously expensive or even unthinkable with actual equipment. Over the last 50 years, airlines and the armed forces have decisively moved to simulations for critical tasks.

In education, we must also consider what tools will best support our learners' progress. As engineering simulations are used routinely for circuit design, engineering education simulations are increasingly used to facilitate learning of circuit design. How safe is it to use learning simulations of this sort? What effect will use of simulated labs have on accreditation?

According to Dan Hodge at the Accreditation Board for Engineering and Technology (ABET), from an accreditation viewpoint ABET's orientation is to outcomes-based assessment. Thus the accreditation board needs no specific policy on use of simulated labs in engineering education, since the issue is to demonstrate outcomes - that whatever methods and tools are used lead to the outcomes specified for the program (Dan Hodge, personal communication, March 25, 2003).

Our research investigates the extent to which we can use tutored simulations to replace some physical electronics labs. This project represents a small part of larger issues related to how people learn [1], how to anchor learning in realistic settings [2], and how we can help people learn most cost effectively $[3,4,5]$.

Hall [6] compared the performance and attitude of students in a freshman introductory laboratory course in direct current circuits and in a junior-level advanced electronics course. Students worked in groups and used four physical labs. They also worked individually using Electronic Workbench software simulations in four additional labs. Hall conducted a similar comparison for juniors in an advanced electronics laboratory course. The results indicated no significant differences in either the freshman-level or the junior-level courses.

The research reported here is part of a series of studies that began with small groups. Bourne, Brodersen, Campbell, Dawant, and Shiavi [7] provide an extended discussion of the model underlying this research. This work was sufficiently encouraging that Campbell, Bourne, Mosterman, \& Brodersen [8] conducted an experimental study as part of an on-campus beginning circuits course. The results indicated that student performance was equivalent to or better than the performance of students using traditional physical labs. The present work replicates that study.

There is a difference between circuit simulations that facilitate design of circuits, and tutored simulations to support learning. The former may provide more powerful design and circuit-testing tools. The latter tend to include basic tutorials (e.g., how to read resistor codes) and coaching. They may also be more interactive and easier for students to use, as discussed by Nahvi [9, 10, 11]. 
Many circuit simulations are used primarily to build and test circuits. Examples are the circuit simulation programs SPICE [12], PSPICE from PSPICE.com [13] or from Cadence [14]; APLAC [15]; and Intusoft ICAP/4 [16]. These are generally oriented to designing circuits more than to facilitating learning, but they typically include reference information and training on how to use the tools.

Other circuit simulations facilitate learning in electronics labs. For example, Multisim 2001, part of the Electronics Workbench product [17] and Circuit Maker [18] are popular circuit capture and simulation systems that are also used for education. Both Circuit Maker and Electronic Workbench may reduce the cost and time of laboratory learning experiences.

To investigate the efficacy of tutored simulations for learning, we used software for which learning is the primary purpose - the Electronic Laboratory Simulator [19]. Our group at Vanderbilt University developed this software over a period of six years. The ELS includes a realistic graphical representation of the breadboard and equipment, as well as schematics. It also provides a built-in tutor that checks circuits and provides both general and problem-specific tutorials. It has been used in universities, public schools, corporations, city government, and by individuals since 1977. The software includes a circuit board and toolbin to build circuits. ELS also provides access to simulated equipment such as a function generator and oscilloscope. The studies reported here investigate the extent to which simulations of electronics circuits, with the addition of realistic high fidelity graphical representations of equipment and immediate computer coaching, may replace some physical electronics laboratories for education.

The purpose of the replication study is to understand the extent to which the original results may have been an artifact of a particular group of students, TAs, or other factors that were unique to the original study. Failure to replicate the results would call for a systematic investigation of factors other than use of simulated electronics labs in the results we obtained. Replication of the results would increase our confidence that a combination of ELS tutored simulations plus physical labs that use TAs can support learning that is equivalent to that of students using all physical labs with TAs. In a more general sense, studies such as this can provide data about the utility of different simulation approaches to increase access for design and use of electronic circuits.

\section{METHOD}

Participants This study involved students at Vanderbilt University who were enrolled in multiple sections of EE213, a sophomore-level beginning circuits lab course in the Electrical Engineering Department taught by two instructors.

Materials: The ELS software used for this study provides interconnected simulation of a power supply, pictorial and schematic breadboard for making connections, digital multimeter, oscilloscope, and function generator. It also provides a set of tutorials and a built-in coach. Nine labs are included, corresponding to a typical one-semester beginning circuits course. The software is described in Mosterman, Dorlandt, Campbell, Burow, Brodersen \& Bourne [20]; Falcon Software [19]; Mosterman, Bourne, Brodersen \& Campbell [21]; and Mosterman, Campbell, Brodersen \& Bourne [22].

Procedure: Participants were assigned to either (a) all physical labs with TA's or (b) a combination of physical labs with TAs and tutored simulated labs using ELS software. The traditional all-physical laboratory treatment was designated the default condition. As part of the protection for human subjects, a student assigned to ELS who began the study but later chose not to take part would be placed in the physical laboratory group. All subjects were given a full description of the study, including potential 
risks, before agreeing to take part.

Some students assigned to the physical lab group wanted to use ELS because of the time flexibility; however, they were required to stay in the physical lab, as originally assigned. Because the potential for movement was only one way (from the experimental ELS treatment to the physical lab), a larger number of people were originally assigned to the ELS condition. This was done using the Bernoulli distribution in the Microsoft Excel data analysis random number generator, by setting the parameter to produce a higher probability of subjects being assigned to the experimental than to the control condition.

Dependent variables were scores on a written pre-test, mid-point test, and post-test, as well as time required by pairs of students to complete the physical lab at the end of the course.

As is typical when laboratory space is limited, many circuits labs were originally scheduled on Friday afternoon or in the evenings. Because ELS can be used when and where students want, the need for physical labs was decreased, and thus the undesirable lab times could be eliminated. Students typically use ELS in their dorm rooms or at home. Students who do not have their own computer use one of the School of Engineering computer labs or a public access lab. No additional computer lab space or time was required. Since there are more weeks in the semester than physical labs, when ELS students needed to use the physical labs there was still time available.

TAs who facilitate ELS do not need to meet their students for three hours each week to facilitate each lab. Since ELS provides built-in tutorials, TAs provided more individualized coaching for learners, at hours when students prefer to work - such as in the evening. This assistance was available to students in both the physical lab group and the combined ELS/physical lab group.

Those who used ELS turned in lab notebooks as is typical for any lab. Since they did not need to come to a lab, we could not verify that the work they submitted was their own. ELS provides a database that records completion of each part of each lab. ELS students turned in a copy of their database file with their lab notebooks, so we increased the odds that they actually completed the lab. Of course they could still have had someone take the ELS lab for them, but we also observed their performance in three physical labs. In addition to providing the students with hands-on physical lab experience, this further increased the odds that they were learning from the labs.

Participants worked in teams on the final lab, which was a physical lab test that was the same for both groups. Since the lab could not be completed until it was done correctly, the score reported for the lab test was the time for a group to complete the assignment.

Only the data from participants who agreed to take part in the study and who completed all three written tests and the required labs are included with the study results.

\section{RESULTS}

At a preset significance level of .05 , there was no significant difference on written pretest performance between the ELS and physical lab groups, with $\mathrm{t}(62)=0.61, \mathrm{p}=\mathrm{n} . \mathrm{s}$. There was a significant difference in favor of ELS on the mid term written test, with $\mathrm{t}(62)=1.91, \mathrm{p}<.05$. The written post-test showed no significant difference between the ELS and physical lab groups, with $\mathrm{t}(62)=.78, \mathrm{p}=\mathrm{n}$.s. There was no significant difference in time required to complete a physical lab at the conclusion of the course, with 
$\mathrm{t}(33)=1.09, \mathrm{p}=$ n.s.

\section{DISCUSSION}

The students who used the ELS simulated labs in combination with physical labs scored as well on both the final written and physical lab tests as those who used all physical labs.

The pretest showed no significant difference between groups. The higher average score of the ELS group on the written midterm test is difficult to interpret, given that the scores were not significantly different on the final written test. This midterm discrepancy may have resulted from better preparation by the ELS students' TA for certain mid-term test questions, although the more experienced TA was assigned to the physical lab group.

The equivalent performance of those who used a combination of ELS and physical labs, to that of those who used only physical labs replicates the earlier experimental studies. There is thus confirming evidence across students that the ELS tutored simulation can replace some physical labs that use TAs. With Hall's work [6], there is also evidence across investigators and software programs. These studies of two different simulated labs with tutorials in software may lead to applications that increase access for students working off-campus or in the late evening, and help decrease equipment and facility costs for learning institutions. As distributed Web-based learning proliferates, the ability to do lab work at home or at a remote location can open new doors of opportunity.

Using off-the-shelf electronic laboratory simulation software, the cost for labs is in the range of \$10-\$120 per station, each of which supports multiple learners.

\section{RELATION TO OTHER SLOAN-C QUALITY PILLARS}

Learning effectiveness: replicated studies indicate comparable effectiveness to physical labs, lower costs per learner, and better access (e.g., learners can work in their own living quarters at night).

Cost-effectiveness: Lab equipment costs are likely to be reduced using simulations to replace some physical labs.

Access: Students generally prefer working at times of their choosing, which often meant late at night, when physical labs were not available. A Lab assistant was available in evenings for either face-to-face help or phone consulting.

Learner satisfaction: Several students requested to transfer to the virtual labs because of the time flexibility (these requests were denied because of random assignment of subjects).

Faculty satisfaction: Faculty members typically preferred physical labs, which might be a barrier to implementation in some contexts.

\section{REFERENCES}


1. Bransford, J. D., A. L. Brown, and R. R. Cocking. How People Learn: Brain, Mind, Experience, and School, Chapter 9. Washington, D.C.: National Academy Press, 1999. Online: http://bob.nap.edu/readingroom/books/howpeople1/.

2. Cognition and Technology Group at Vanderbilt. Anchored Instruction and Situated Cognition Revisited. Educational Technology 33(1): 52-70, 1993.

3. Campbell, J. O. Factors in ALN Cost Effectiveness at BYU. In J. R. Bourne \& J. C. Moore (Eds.), Elements of Quality Online Education, 59-69. Needham, MA: Sloan-C, 2002.

4. Campbell, J. O. Review of the article, Instructor Attitudes within the SCALE Efficiency Projects. In J. R. Bourne, (Ed.), OnLine Education: Learning Effectiveness and Faculty Satisfaction, 207-210. Needham, MA: Sloan-C, 2000.

5. Phillips, J. J. Handbook of Training Evaluation and Measurement Methods, 2nd ed. Houston: Gulf Publishing Company, 1991.

6. Hall, T. M. A Quantitative Analysis of the Effectiveness of Simulated Electronics Laboratory Experiments. Journal of Engineering Technology, Fall 2000.

7. Bourne, J. R., A. J. Brodersen, J. O. Campbell, M. M. Dawant, and R. G. Shiavi. A Model for On-line Learning Networks in Engineering Education. Journal of Engineering Education 85(3): 253262, Jul. 1996.

8. Campbell, J. O., J. R. Bourne, P. Mosterman, and A. J. Brodersen. The Effectiveness of Learning Simulations for Electronic Laboratories. Journal of Engineering Education 91(1): 81-87, 2002.

9. Nahvi, M. J. Dynamics of Student-Computer Interaction in a Simulation Environment: Reflections on Curricular Issues. Presented at the Frontiers in Education Conference, Salt Lake City, Utah, November, 1996.

10. Nahvi, M. J. Effective Interaction with the Computer: Observations and Models from an Eight-year Experience. Presented at the ASEE Annual Conference, Seattle, Washington, July, 1998.

11. Nahvi, M. J. Interactive Modules for Electric Circuits. Presented at the ASEE Annual Conference, St. Louis, Missouri, June 18-21, 2000.

12. SPICE. (2003, Mar.). Online. Available: http://bwrc.eecs.berkeley.edu/Classes/IcBook/SPICE/.

13. Orcad PCB. 2003, Mar. Online. Available: http://www.orcadpcb.com/.

14. Cadence. 2003, Mar. Online. Available: http://www.orcad.com/.

15. APLAC. 2003, Mar. Online Available: http://www.aplac.com/.

16. Intusoft ICAP/4. 2003, Mar. Online. Available: http://www.i-t.com/engsw/intusoft/icap.htm .

17. Electronic Workbench. 2003, Mar. Online. Available: http://www.electronicsworkbench.com/.

18. CircuitMaker. 2003, Mar. Online. Available: http://www.microcode.com/.

19. Falcon Software. 2003, Mar. Online. Available: http://www.falconsoftware.com/index.htm.

20. Mosterman, P. J., M. A. M Dorlandt, J. O. Campbell, C. Burrow, R. Bouw, A. J. Brodersen, and J. R. Bourne. Virtual Engineering Laboratories: Design and Experiments. Journal of Engineering Education 83(3): 279-285, 1994.

21. Mosterman, P. J., J. R. Bourne, A. J. Brodersen, and J. O. Campbell. Electronics Laboratory Simulator Instructor Manual, Laboratory Manual, and Reference Manual. Wentworth, NH: Falcon Software, 1995.

22. Mosterman, P. J., J. O. Campbell, A. J. Brodersen, and J. R. Bourne. Design and Implementation of an Electronics Laboratory Simulator. IEEE Transactions on Education 39(3): 309-313, Aug. 1995.

\section{ACKNOWLEDGEMENTS}

The work reported here was supported by the Alfred P. Sloan Foundation, the National Science Foundation (grant USE-9156244), Vanderbilt University School of Engineering, Microsoft Corporation, Falcon Software, and Hewlett Packard. 